\title{
Assessment of Lipid Dysfunction of Patients Under Haemodialysis in Cameroon
}

\author{
Cédric Gueguim ${ }^{1}$, Lucien Etamé Soné ${ }^{1,2}$, Henriette Thérèse Dimodi ${ }^{1,2}$, Marie Patrice Halle ${ }^{3}$, \\ François Kaze Folefack ${ }^{4}$, Constant Anatole Pieme ${ }^{4}$, Nnanga Nga ${ }^{2,3,4}$, Wilfred Mbacham ${ }^{1,4}$ \\ ${ }^{1}$ Départment of Biochemistry, University of Yaoundé I, Central Region, Cameroon \\ ${ }^{2}$ Institute of Medical Research and Medicinal Plants (IMPM), Central Region, Cameroon \\ ${ }^{3}$ Faculty of Medicine and Pharmaceutical Sciences, University of Douala, Littoral Region, Cameroon \\ ${ }^{4}$ Faculty of Medicine and Biomédical Sciences, University of Yaoundé I, Central Region, Cameroon
}

Email address:

guecedricfr@yahoo.fr (C. Gueguim),ngnnanga@yahoo.fr (N. Nga)

\section{To cite this article:}

Cédric Gueguim, Lucien Etame Sone, Henriette Thérèse Dimodi, Marie Patrice Halle, François Kaze Folefack, Constant Anatole Pieme, Nnanga Nga, Wilfred Mbacham. Assessment of Lipid Dysfunction of Patients Under Haemodialysis in Cameroon. American Journal of Biomedical and Life Sciences. Vol. 5, No. 4, 2017, pp. 63-68. doi: 10.11648/j.ajbls.20170504.11

Received: April 18, 2017; Accepted: May 6, 2017; Published: July 6, 2017

\begin{abstract}
Dyslipidaemia is a major risk factor of cardiovascular disease of patients under haemodialysis. Both increase and decrease of cholesterol levels are associated with higher cardiovascular mortality rate in haemodialysis patients. The objective of this study was to assess the lipid dysfunction among patients maintained under haemodialysis in two reference centres of haemodialysis in Cameroon. A descriptive comparative study was carried out in Nephrology Unit of the University Teaching Hospital of Yaoundé and the same Unit of the Douala General Hospital, Cameroon. A total of 160 subjects were studied: Of these, there were 80 patients under haemodialysis and 80 healthy controls. Body mass index (BMI) was measured according to WHO's guidelines. Serum total cholesterol (TC), triglycerides (TG) and high-density lipoprotein cholesterol (HDL-C) were assayed before and after haemodialysis session. Low-density lipoprotein cholesterol (LDL-C) was calculated using Friedwald's equation. Their cardiovascular risk indices (TC / HDL-C) were also determined. Patients under haemodialysis had significantly lower BMI as compared with the healthy controls $(\mathrm{p}<0.05)$. Total Cholesterol, LDL-C and HDL-C were considerably lower before and after haemodialysis compared with the healthy controls $(p<0.05)$. A non-significant difference was found between Triglycerides before and after haemodialysis in contrast with the healthy controls $(\mathrm{p}>0.05)$. The cardiovascular risk indices (TC / HDL-C) of the patients under haemodialysis were higher than those of the healthy control group. Patients under haemodialysis had quite low BMI, total Cholesterol, LDL-C and HDL-C depicting malnutrition leading to inflammation, accelerated atherosclerosis process and cardiovascular complications.
\end{abstract}

Keywords: Total Cholesterol, Lipoproteins, BMI, Haemodialysis, Cardiovascular Disease

\section{Introduction}

Dyslipidaemia is highly prevalent in patients on maintenance haemodialysis (MHD), with predominance of the atherogenic triad, i.e. hypertriglyceridemia, elevated very low density lipoprotein (VLDL) and reduced high-density lipoprotein (HDL) [1]. This mimics the lipid abnormalities of metabolic syndrome, which accelerate the progression of atherosclerosis and increase the risk for cardiovascular mortality [2]. Patients with chronic kidney disease (CKD) are in the highest risk category, i.e. a coronary heart disease
(CHD) risk equivalent, for risk factor management of cardio vascular disease [3]. The incidence of cardiovascular disease is high in patients under haemodialysis [4], coronary heart disease risk factors in the general population remain predictive of cardiovascular disease (CVD) among patients with CKD [5]. Cardiovascular disease is the major cause of death in haemodialysis patients, accounting for almost 50 percent of deaths [6]. Many atherosclerotic cardiovascular disease (ASCVD) risk factors are prevalent more in the end 
stage renal disease (ESRD) than in the general population. Of the traditional risk factors for atherosclerotic cardiovascular disease ASCVD in patients with end stage renal disease ESRD, dyslipidaemia may play a major role. Control of these risk factors may have a substantial impact in reducing the excess burden of coronary heart disease [7]. Cholesterol levels may be lower in patients under haemodialysis. In this setting, there is an inverse relationship between mortality and the cholesterol concentration [8]. This pattern of reverse epidemiology, i.e. hypercholesterolemia associated with decreased mortality and low cholesterol concentration in patients under haemodialysis associated with increased CVD mortality has been associated with malnutrition inflammation atherosclerosis complex [9-10]. Keeping in view, the mortality associated with CVD in haemodialysis patients and the association of cholesterol levels with CVD in patients under haemodialysis, we planned to study the lipid profile of patients under haemodialysis in two reference centres of haemodialysis in Cameroon by comparison to healthy controls. This study was done to understand the burden and the type of lipid dysfunction in patients undergoing haemodialysis, in order to adopt appropriate measures to decrease CVD mortality rate within this population.

\section{Methodology}

\subsection{Study Population, Sample Size and Sample}

This study was carried out in the Nephrology Unit of the University Hospital Center of Yaoundé (CHUY) and the Nephrology Unit of the Douala General Hospital, Cameroon. Eighty patients (45 men and 35 women), aged between 20 and 75 years with end-stage renal disease (ESRD) who were placed on dialysis two times per week for 4 hours with the use of Polysulfone membranes, were included. Also, a control group of healthy volunteers made up of 80 healthy people (45 men and 35 women), aged between 28 and 65 years, were also recruited. None among the patients was a smoker, an alcoholic or was suffering from HIV/AIDS. A research authorization $\quad \mathrm{N}^{\mathrm{O}} \quad 191$ AR/MINSANTE/HGD/DM/07/15 issued by the Medical Service of the Douala General Hospital was obtained for the study as well as an authorization from the General Directorate of the Yaoundé Hospital and University Centre was obtained. Ethical clearance $\mathrm{N}^{\mathrm{o}}$ 2015/12/709/CE/CNERSH/SP was also obtained from the National Ethics Committee on Research on Human Health and a duly signed consent form from each patient who participated in the study was also obtained before inclusion in the study.

\subsection{Anthropometric Measurements}

Clinical history and physical examination of each subject was carried out. The height and weight of all individuals were measured using a measuring scale and weighing machine. Body Mass Index (BMI) was calculated in $\mathrm{kg} / \mathrm{m}^{2}$.

\subsection{Blood Sampling, Processing and Biochemical Analysis}

Four ml of blood samples were collected in dry tubes at the end of the fistula needle before and after dialysis for the analysis of the lipid parameters in the biochemical laboratory of the Faculty of Medicine and Biomedical Sciences of the University of Yaoundé 1. Serum total cholesterol (TC) was estimated by enzymatic cholesterol-colorimetric test CHODPOD. Liquid [11] and Serum triglycerides by enzymaticcolorimetric test GPO-POD [12]. Serum high-density lipoprotein cholesterol (HDL-C) by enzymatic colorimetric method. Low-density lipoproteins cholesterol (LDL-C) was calculated using Friedwald's equation:

$$
\mathrm{LDL}-\mathrm{C}=\mathrm{TC}-(\mathrm{HDL}-\mathrm{C}+\mathrm{TG} / 5) \text { [13]. }
$$

\subsection{Data Analysis}

Data was statistically analysed using the software Statistica10 of Statsoft. Means, standard error and percentages were calculated. An ANOVA one-way analysis (PostHoc Fisher LSD) was performed to assess the significance of the differences observed between the values obtained. A p value $<0.05$ was taken as significant.

\section{Results}

\subsection{Personal Characteristics of Study Groups}

One hundred and sixty subjects, 80 control and 80 MHD patients, completed the study. Forty five individuals were male and 35 were females in each group (Figure 1). The age range of control and test subjects were $20-75$ years with a mean \pm standard error of $48.69 \pm 12.5$ and $47.70 \pm 13.08$ for patients under haemodialysis and control groups respectively.

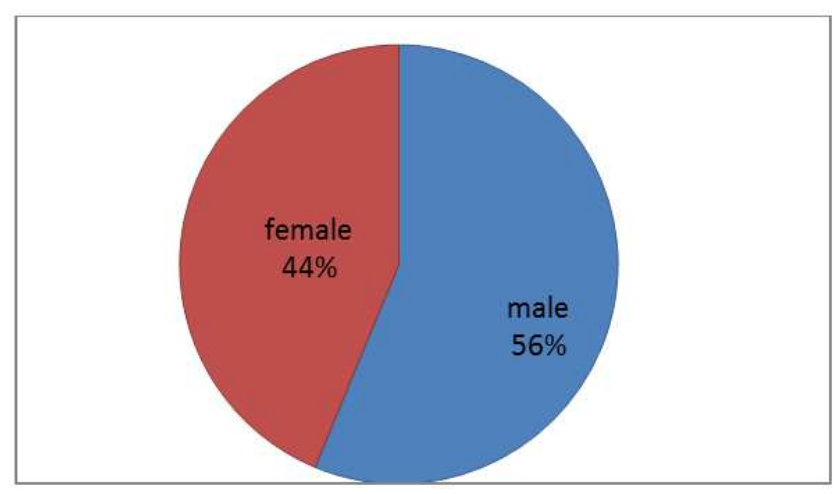

Figure 1. Sex distribution of study subjects.

\subsection{Distribution of BMI Among Patients Under Haemodialysis and Controls}

The patients under haemodialysis had lower BMI compared to controls. The standard errors were calculated and shown to be $23.50 \pm 3.45$ vs $25.68 \pm 4.18$ (Figure 2). 


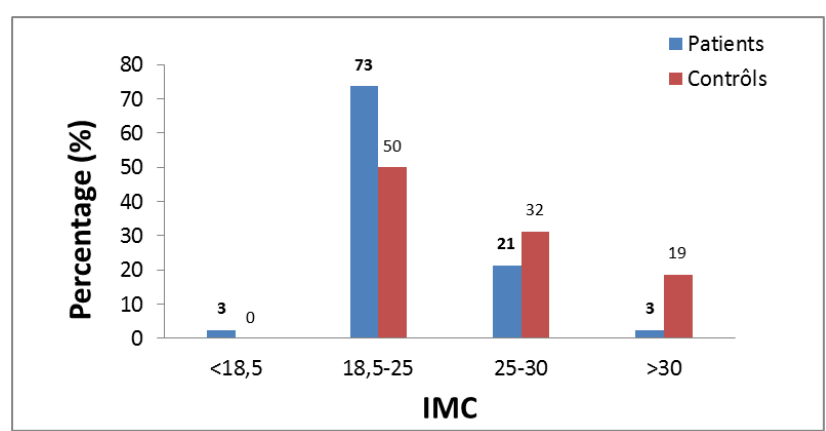

Figure 2. Distribution of BMI among patients under haemodialysis.

\subsection{Lipid Profile of 160 Study Individuals Before and After Haemodialysis}

The Total Cholesterol (TC), the LDL-C and the HDL-C of MHD patients were considerably lower before and after haemodialysis in contrast with the healthy controls as shown in Table-1. Non-significant difference was found between Triglycerides before and after haemodialysis as compared with the controls $(\mathrm{p}>0.05)$. The cardiovascular risk indices TC / HDL-C of the chronic renal failure patients were higher before and after haemodialysis than that of the controls.

Table 1. Lipid Profile of 160 Study Individuals.

\begin{tabular}{|c|c|c|c|}
\hline \multirow{2}{*}{$\begin{array}{l}\text { Serum Cholesterol/ } \\
\text { Triglycerides (g/L) }\end{array}$} & \multicolumn{2}{|c|}{ patients on haemodialysis Mean \pm standard error $(n=80)$} & \multirow{2}{*}{$\begin{array}{l}\text { Controls } \\
\text { Mean } \pm \text { standard error }(n=80)\end{array}$} \\
\hline & Before haemodialysis & After haemodialysis & \\
\hline Total Cholesterol & $0.75 \pm 0.49^{\mathrm{a}}$ & $0.88 \pm 0.45^{\text {a }}$ & $1.26 \pm 0.85^{\mathrm{b}}$ \\
\hline LDL cholesterol & $0.48 \pm 0.46^{\mathrm{a}}$ & $0.56 \pm 0.45^{\mathrm{a}}$ & $0.79 \pm 0.65^{b}$ \\
\hline HDL cholesterol & $0.24 \pm 0.19^{\mathrm{a}}$ & $0.25 \pm 0.22^{\mathrm{a}}$ & $0.36 \pm 0.35^{b}$ \\
\hline Triglycerides & $0.69 \pm 0.38^{a}$ & $0.62 \pm 0.35^{\mathrm{a}}$ & $0.63 \pm 0.42^{\mathrm{a}}$ \\
\hline TC/HDL-C & $6.16 \pm 8.23^{\mathrm{ab}}$ & $8.7 \pm 13.20^{b}$ & $5.64 \pm 4.27^{\mathrm{a}}$ \\
\hline
\end{tabular}

NB: In the same column, the values subscripted with different letters are significantly different $(p<0.05)$

\subsection{Comparison of Lipid Profile of Male Patients Under Haemodialysis and Controls}

TC, LDL-C, HDL-C and TG of male patients under haemodialysis were remarkably lower before and after haemodialysis in comparison with the controls (Table 2). The cardiovascular risk indices TC/HDL-C of the male patients did not change before and after haemodialysis as compared to the controls

Table 2. Comparison of lipid profile of male patients under haemodialysis and controls.

\begin{tabular}{|c|c|c|c|}
\hline \multirow{2}{*}{$\begin{array}{l}\text { Serum Cholesterol/ } \\
\text { Triglycerides (g/L) }\end{array}$} & \multicolumn{2}{|c|}{ Male patients under haemodialysis Mean \pm standard error $(n=45)$} & \multirow{2}{*}{$\begin{array}{l}\text { Controls } \\
\text { Mean } \pm \text { standard error }(n=45)\end{array}$} \\
\hline & Before haemodialysis & After haemodialysis & \\
\hline Total Cholesterol & $0.61 \pm 0.37^{\mathrm{a}}$ & $0.72 \pm 0.29^{a}$ & $1.05 \pm 0.69^{\mathrm{b}}$ \\
\hline LDL cholesterol & $0.35 \pm 0.33^{\mathrm{a}}$ & $0.4 \pm 0.27^{\mathrm{a}}$ & $0.61 \pm 0.49^{b}$ \\
\hline HDL cholesterol & $0.25 \pm 0.22^{\mathrm{a}}$ & $0.25 \pm 0.21^{\mathrm{a}}$ & $0.33 \pm 0.35^{\mathrm{a}}$ \\
\hline Triglycerides & $0.64 \pm 0.41^{\mathrm{ab}}$ & $0.52 \pm 0.27^{\mathrm{a}}$ & $0.71 \pm 0.45^{b}$ \\
\hline TC/HDL-C & $4.32 \pm 4.70^{\mathrm{a}}$ & $4.93 \pm 4.72^{\mathrm{a}}$ & $5.81 \pm 4.10^{\mathrm{a}}$ \\
\hline
\end{tabular}

NB: In the same column, the values subscripted with different letters are significantly different $(\mathrm{p}<0.05)$

\subsection{Comparison of Lipid Profile of Female Patients Under Haemodialysis and Controls}

TC, LDL-C, and HDL-C of female patients were notably lower before and after haemodialysis as compared with the control group (Table 3). The triglycerides of female patients were higher before and after haemodialysis in contrast with the control group (Table 3). The cardiovascular risk indices TC/HDL-C of the female patients were higher before and after haemodialysis than that of the control group.

Table 3. Comparison of lipid profile of female patients under haemodialysis and controls.

\begin{tabular}{llll}
\hline $\begin{array}{l}\text { Serum Cholesterol/ } \\
\text { Triglycerides }(\mathbf{g} / \mathbf{L})\end{array}$ & \multicolumn{2}{l}{ Female patients under haemodialysis Mean \pm standard error $(\mathbf{n}=\mathbf{3 5})$} & $\begin{array}{l}\text { Controls } \\
\text { Mean } \pm \text { standard error }(\mathbf{n}=\mathbf{3 5})\end{array}$ \\
\cline { 2 - 3 } & Before haemodialysis & After haemodialysis & $1.52 \pm 0.97^{\mathrm{b}}$ \\
Total Cholesterol & $0.93 \pm 0.57^{\mathrm{a}}$ & $1.1 \pm 0.52^{\mathrm{a}}$ & $1.02 \pm 0.77^{\mathrm{b}}$ \\
LDL cholesterol & $0.65 \pm 0.54^{\mathrm{a}}$ & $0.76 \pm 0.55^{\mathrm{ab}}$ & $0.39 \pm 0.35^{\mathrm{b}}$ \\
HDL cholesterol & $0.23 \pm 0.14^{\mathrm{a}}$ & $0.25 \pm 0.24^{\mathrm{a}}$ & $0.53 \pm 0.35^{\mathrm{b}}$ \\
Triglycerides & $0.75 \pm 0.33^{\mathrm{a}}$ & $0.73 \pm 0.40^{\mathrm{a}}$ & $5.43 \pm 4.53^{\mathrm{a}}$ \\
TC/HDL-C & $8.53 \pm 10.89^{\mathrm{ab}}$ & $13.54 \pm 18.26^{\mathrm{b}}$ & \\
\hline
\end{tabular}

NB: In the same column, the values subscripted with different letters are significantly different $(\mathrm{p}<0.05)$

\section{Discussion}

This study determined the lipid profile along with BMI of patients undergoing maintenance haemodialysis (MHD) in two reference centres of haemodialysis in Cameroon in order to adopt appropriate measures to reduce the mortality rate in patients under haemodialysis. The haemodialysis patients had significantly lower BMI by comparison to controls ( $p<$ 
0.05). Several other studies have shown similarly lower BMI in MHD patients as compared with controls [14-15]. The results showed $73 \%$ normal weight, $21 \%$ overweight and $3 \%$ obese patients undergoing haemodialysis in comparison to $59 \%$ normal weight, $24 \%$ overweight and $17 \%$ obese individuals undergoing haemodialysis as reported by Torun and associates [16]. On the other hand, 3\% of MHD patients had BMI less than $18.5 \mathrm{~kg} / \mathrm{m}^{2}$ in contrast with none in the control group. This indicates increased prevalence of malnutrition in our MHD patients according to WHO's guidelines for adults [17]. Survival among haemodialysis patients is enhanced in over weight individuals [18]. Every one-unit increase in the BMI is associated with a reduction of $30 \%$ in the relative risk of dying [19].

TC, LDL-C and HDL-C was significantly lower before and after haemodialysis in patients under haemodialysis as compared to healthy controls $(\mathrm{p}<0.05)$. Kalantar-Zadeh et al also observed lower total cholesterol, LDL-C and HDL-C in patients under haemodialysis compared to healthy controls, which is similar to our study [20]. However serum HDL-C was non-significantly lower before and after haemodialysis in male patients under haemodialysis in comparison with the controls ( $p>0.05)$. HDL-C $<27 \mathrm{mg} / \mathrm{dl}$ was found before and after haemodialysis in $65 \%$ of patients under haemodialysis in contrast to $81 \%$ and $51 \%$ incidence found by Ashfaq et al [21] and by Pennell et al [1] respectively.

In this study only $2 \%$ of patients had serum TG levels more than $16 \mathrm{mg} / \mathrm{dl}$. In CHOICE study, $36 \%$ of patients under haemodialysis had hypertriglyceridemia whereas Pennell and co-workers found the incidence to be 52\% [122]. Non-fasting sample collection by Pennell may be the cause of this difference as triglyceride levels increase after meals. Of the same, the 24-hour dietary recall during sample collection shows that only $30 \%$ of our patients had a high-fat diet. This may also explain this low rate of hypertriglyceridemia. Female patients in this study had lower TC, LDL-C, HDL-C and TG compared to healthy controls but the difference was not statistically significant before and after dialysis $(\mathrm{p}>0.05)$. Also in the female, their cardiovascular risk indices increase notably before and after haemodialysis as compared to healthy controls. Small sample size may be one reason for this observation. The other reason may be that, the mean age of the female patients under haemodialysis was 45 years and almost $66 \%$ of them were postmenopausal. After menopause serum total cholesterol and LDL cholesterol increase and HDL cholesterol decreases [23-24]. This is as a result of a decrease in the levels of oestrogen. Females are likely to have early menopause and have unfavourable lipid profile for CVD in ESRD [25].

In this study, $3 \%$ of the patients would have required treatment as per Kidney Dialysis Outcome Quality Initiative (K/DOQI) guidelines versus 37\% in Ashfaq et al study [21]. This high percentage of MHD patients having low cholesterol and lower percentage qualifying treatment for hyperlipidaemia again indicates malnutrition. The general population also has lower incidence of hyperlipidaemia [26]. Total and LDL hypercholesterolemia as well as hypertriglyceridemia have a paradoxical association with better survival [27]. Low serum cholesterol in MHD patients is associated with increased CVD mortality. This pattern of reverse epidemiology for CVD risk factors has been associated with malnutrition-inflammationcomplex syndrome/malnutrition inflammation-atherosclerosis complex (MICS/MIA) [28]. Both malnutrition and inflammation are common in CKD patients, are associated with high short-term mortality in haemodialysis patients and appear to be the main cause of worsening ASCVD in CKD patients [29-30].

Malnutrition may lead to inflammation and vice versa [31]. Malnourished dialysis patients are hypocholesterolemic, deficient in antioxidants and are predisposed to infection that may decrease the ability to clear circulating endotoxins [31]. Based upon the lipoprotein-endotoxin hypothesis, there is an optimum serum lipoprotein concentration below which lipid reduction is detrimental as it leads to decreased ability of lipoproteins to bind lipopolysaccharide; this, in turn, may prevent lipoproteins from neutralizing the detrimental effects of endotoxin [32]. Uraemia and renal replacement therapies result in markedly enhanced oxidative stress, the production of complement fragments and cytokines, increased adhesion molecules in endothelial cells, and other pro-inflammatory factors [33]. These factors may provide the proper milieu for the development of accelerated atherosclerosis [34].

Successful management of MICS may ameliorate the cardiovascular mortality and poor outcome in dialysis patients. Because MICS is multifactorial, its correction will require an integral approach rather than a single intervention [28]. The early stage of chronic renal failure may be the ideal time to start therapeutic interventions [35].

Routine counselling and encouragement for physical activity in MHD patients has the potential to improve physical functioning, and optimise quality of life [36]. For MHD patients, incorporation of exercise into the dialysis session may increase patient participation and tolerance of exercise. A study in normal adults concludes that a regular exercise program can improve plasma lipid and lipoprotein patterns, results, which should be applicable to haemodialysis patients as well [37]. MHD patient can adhere to long-term physical training programs on the non-dialysis days, as well as during haemodialysis with considerable improvements in physical fitness and health [38]. Further studies are needed in different haemodialysis centres in large number of patients especially in female patients in this country to know the impact of different strategies adopted to ameliorate malnutrition, inflammation and cardiovascular disease in haemodialysis patients in the set-up.

\section{Conclusion}

Hypocholesterolemia and decrease HDL-C along with low BMI are prevalent in patients undergoing haemodialysis. This may increase the mortality rate in these patients through malnutrition inflammation-atherosclerosis complex, process leading to cardiovascular disease complications. This risk is also evident in the higher ratio of cardiovascular risk indices, 
TC/HDL-C in females. Dietary education of MHD patients, improvement in dialysis practices and inclusion of exercise programmes in dialysis centres is likely to improve CVD mortality in patients under haemodialysis.

\section{References}

[1] Pennell P, Leclercq B, Delahunty M, Walters B. (2006). The utility of non-HDL in managing dyslipidemia of stage 5 chronic kidney diseases. Clinic Nephrolog., 66 (5), 336-47.

[2] Abrass C. (2006). Lipid metabolism and renal disease. Contrib Nephrology. 151: 106-21.

[3] National Kidney Foundation. K/DOQI clinical practice guidelines for chronic kidney disease (2002). Evaluation, classification, and stratification. American Journal of Kidney Disease. 39: S1-266.

[4] Gowdak L, Arantes R, Krieger E. (2007). Under use of American College of Cardiology/American Heart Association Guidelines in haemodialysis patients. Ren Fail. 29 (5), 559-65.

[5] Soubassi L, Papadakis E, Theodoropoulos I, Poulos G, Chaniotis D, Tsapakidis I., et al. (2007). Incidence and risk factors of coronary artery disease in patients on chronic hemodialysis., International Artif Organs. 30 (3), 253-7.

[6] Wakeel S, Mitwalli A, Mohaya S, Abu-Aisha H, Tarif N, Malik G., et al (2002). Morbidity and mortality in ESRD patients on dialysis. Saudi Journal of Kidney Disease Transplantation. October-December; 13 (4): 473-7.

[7] Muntner P, He J, Astor B, Folsom A, Coresh J. (2005). Traditional and nontraditional risk factors predict coronary heart disease in chronic kidney disease: results from the atherosclerosis risk in communities study. American Journal of Nephrology. 16 (2): 529-38.

[8] Iseki K, Yamazato M, Tozawa M, Takishita S. (2002). Hypocholesterolemia is a significant predictor of death in a cohort of chronic hemodialysis patients. Kidney International Journal. 61: 1887-93.

[9] Liu Y, Coresh J, Eustace J, Longenecker J, Jaar B, Fink N., et al.(2004). Association between cholesterol level and mortality in dialysis patients: role of inflammation and malnutrition. JAMA, 291: 451-9.

[10] Kalantar-Zadeh K, Block G, Humphreys M, Kopple J. (2003). Reverse epidemiology of cardiovascular risk factors in maintenance dialysis patients. Kidney International Journal, 63 (3): 793-808.

[11] Allain C, Poon L, Richmond, W and Fu. (1974). Enzymatic determination of serum cholesterol. P. D. Clin. Chem, 20: 470.

[12] Fossati R, Prencipe L. (1982). Serum triglycerides determined colorimetrically with an enzyme that produces hydrogen peroxide. Clin Chem, 28: 2077.

[13] Friedwald W, Levy R, Fredrickson D. (1972) Estimation of the concentration of low-density lipoprotein cholesterol in plasma without use of preparative ultracentrifuge. Clin Chem, 18: 499-502.

[14] Bednarek-Skublewska A, Baranowicz-Gaszczyk I, Jóźwiak L, Dzik M, Majdan M, Ksiazek A. (2005). Comparison of some nutritional parameters in hemodialysis patients over and below 65 years of age. Pol Arch Med Wewn. 113 (5): 417-23.

[15] Basaleem H, Alwan S, Ahmed A, Al-Sakkaf K.(2004). Assessment of the nutritional status of end-stage renal disease patients on maintenance hemodialysis. Saudi Journal Kidney Disease Transplantation. October-ecember; 15 (4): 455-6.

[16] Torun D, Micozkadioglu H, Torun N, Ozelsancak R, Sezer S, Adam F., et al.(2007). Increased body mass index is not a reliable marker of good nutrition in hemodialysis patients. Ren Fail. 29 (4): 487-93.

[17] Physical status: the use and interpretation of anthropometry. (1995). Report of a WHO Expert Committee. Geneva, World health Organization, WHO Technical Report Series, No. 854.

[18] Johansen K, Young B, Kaysen G, Chertow G. (2004). Association of body size with outcomes among patients beginning dialysis. American Journal of Clinical Nutrition. 80: 324-32.

[19] Leavey S, McCullough K, Hecking E, Goodkin D, Port F, Young E. (2001). Body mass index and mortality in 'healthier' as compared with 'sicker' haemodialysis patients: Results from the Dialysis Outcomes and Practice Patterns Study (DOPPS). Nephrol Dial Transplant. 16: 2386-94.

[20] Kalantar-Zadeh K, Kilpatrick R, Kopple J, Stringer W. (2005). A matched comparison of serum lipids between hemodialysis patients and nondialysis morbid controls. Hemodialysis International Journal. Jul; 9 (3): 314-24.

[21] Ashfaq A, Abdul H, Dilshad A, Muhammad K, Fatima T, Imran S. (2007): Assessment of lipid dysfunction in patients on maintenance haemodialysis; J Ayub Med Coll Abbottabad 19 (4): 32-36.

[22] Longenecker J, Coresh J; Powe N; Levey A; Fink N; Martin A., et al. (2002). Traditional cardiovascular disease risk factors in dialysis patients compared with the general population: the CHOICE Study. American Journal of Nephrology. 13 (7): 1918-27.

[23] Caparevic Z, Kostic N.(2007). The influence of age and the beginning of menopause on the lipid status, LDL oxidation, and CRP in healthy women. Srp Arh Celok Lek. 2007 MayJun; 135 (5-6): 280-5.

[24] Trémollieres F, Pouilles J, Cauneille C, Ribot C. (1999). Coronary heart disease risk factors and menopause: a study in 1684 French women. Atherosclerosis. 142 (2): 415-23.

[25] Jang C, Bell R, White V, Lee P, Dwyer K, Kerr P., et al. (2001). Women's health issues in haemodialysis patients. Med J Aust. 175 (6): 298-301.

[26] Shamim A, Ihteshamul H. (2004). Association of ABO, Rh blood groups systems with lipids and other anthropometric co variables as predictors of cardiovascular risk in NWFP, Pakistan. Ann King Edward Med Coll. 10 (2): 166-9.

[27] Kilpatrick R, McAllister C, Kovesdy C, Derose S, Kopple J, Kalantar-Zadeh K. (2007) Association between serum lipids and survival in hemodialysis patients and impact of race. American Journal of Nephrology. 18 (1): 293-303.

[28] Kalantar-Zadeh K. (2005). Recent advances in understanding the malnutrition-inflammation-cachexia syndrome in chronic kidney disease patients: What is next? Semin Dialysis. SepOct; 18 (5): 365-9. 
[29] Kalantar-Zadeh K, Ikizler T, Block G, Avram M, Kopple J (2003). Malnutrition-inflammation complex syndrome in dialysis patients: causes and consequences. American Journal of Nephrology. 42 (5): 864-81.

[30] Kharrat I, Jmal A, Jmal L, Amira Z, Cheikh W, Bourouba B et al (2012). Altération du métabolisme lipidique chez les hémodialysés. La Tunisie Medicale. 90 (07): 537-541.

[31] Deicher R, Ziai F, Bieglmayer C, Schillinger M, Horl W. (2005). Low total vitamin C plasma level is a risk factor for cardiovascular morbidity and mortality in hemodialysis patients. American Journal of Nephrology. 16 (6): 1811-8.

[32] Rauchhaus M, Coats A, Anker S. (2000) The endotoxinlipoprotein hypothesis. Lancet. 356 (9233): 930-3.

[33] Horl W, Cohen J, Harrington J, Madias N, Zusman C. (2004). Atherosclerosis and uremic retention solutes. Kidney International Journal 66 (4): 1719-31.
[34] Bro S, Bentzon J, Falk E, Andersen C, Olgaard K, Nielsen L (2003). Chronic renal failure accelerates atherogenesis in apolipoprotein E-deficient mice. American Journal of Nephrology. 14 (10): 2466-74.

[35] Pawlaczyk K, Oko A, Lindholm B. (2003). Czekalski S. Malnutrition-inflammation-atherosclerosis (MIA syndrome) in patients with renal failure. Pol Merkur Lekarski. 15 (88): 334-43.

[36] Painter P. (2005). Physical functioning in end-stage renal disease patients. Hemodialysis International Journal. 9 (3): 218-35.

[37] Iffat A, Riffat K, Imran A, Munir A. (2000). The Effect of Physical fitness on Plasma Lipids in Young Pakistani Male Medical Students. J Rawal Med Coll Dec 2000; 4 (1-2): 34-8.

[38] Kouidi E, Grekas D, Deligiannis A, Tourkantonis A. (2004). Outcomes of long-term exercise training in dialysis patients: comparison of two training programs. Clinical Nephrologie. 61: S31-8. 